\title{
Using Smart Control System to Enhancement the Split Air Conditioning System Performance
}

\author{
Farag Mahel Mohammed* Jamal Abdul-Kareem Mohammed** \\ Mustafa Abdul-Sattar Jabbar**** \\ *,**,***Department of Electromechanical Engineering / University of Technology \\ *Email: drfaragmahel@yahoo.com \\ **Email: jamalshwesh@gmail.com \\ ***Email: mustafa4eem@yahoo.com
}

(Received 15 march 2016; accepted 5 May 2016)

http://dx.doi.org/10.22153/kej.2016.05.001

\begin{abstract}
In IRAQ, the air conditioners are the principal cause of high electrical demand. In summer, the outer temperature sometimes exceeds $50^{\circ} \mathrm{C}$ which significantly effects on the $\mathrm{A} / \mathrm{C}$ system performance and power consumed. In the present work, the improvement in mechanical and electrical performance of split $\mathrm{A} / \mathrm{C}$ system is investigated experimentally and analytically. In this paper, performance and energy saving enhancement of a split-A/C system was experimentally investigated to be efficiently compatible with elevated temperature weathers. This improvement is accomplished via Smart Control System integrate with Proportional-Integral- Differential PID algorithm. The PIC16F877A micro-controller has been programmed with the PID and PWM codes to control the speed of the proposed DC condenser fan over wide range of speed, also it has been programmed to have a smart characteristics to protect the $\mathrm{A} / \mathrm{C}$ system parts as the ability to detect a refrigerant leakage, condenser fan stop, and any obstacles for the fan air flow. A comparative study between the conventional and enhanced $\mathrm{A} / \mathrm{C}$ system is performed. The results show that the proposed system exhibits better performance and saves more energy than the conventional one. The Coefficient of Performance (COP) of the split- A/C system are improved by about $20.56 \%$.
\end{abstract}

Keywords: Split air conditioner A/C, Temperature control, Fan drive, PID controller, PIC16F877A microcontroller.

\section{Introduction}

Air Conditioning $(\mathrm{A} / \mathrm{C})$ system operates to modify an air attributes (temperature and humidity) for more comfortable circumstances. This could be achieved by distributing the conditioned air into an appropriated space like a building, house or vehicle to enhance thermal comfort and indoor air quality. Air conditioners are the principal cause of high electrical demand. In Iraq country during summer, the outer temperature, sometimes, exceeds $50^{\circ} \mathrm{C}$ [1]. Splittype air conditioners are widely used in residential and commercial buildings in this country. The condenser unit is used in the $\mathrm{A} / \mathrm{C}$ system for heat rejection process, which is mostly air cooled condenser. The operation of air cooled condensers is more economic if compared with water cooled and evaporative-cooled condensers. The performance of an $\mathrm{A} / \mathrm{C}$ system may be enhanced via reducing the compressor power consumption, increasing the cooling capacity and heat rejection, decreasing the refrigerant pressure losses, or reducing the difference in pressure between condenser and evaporator.

$\mathrm{Yu}$ and Chan [2] presented how the Coefficient of Performance of air-cooled chillers can be enhanced by using variable speed condenser fan. The condenser fan has number of speed stages for giving the required air flow. The Condensing Temperature Control (CTC) system was used in order to achieve maximum COP. With this control 
system, the condensation temperature is adjusted based on the chiller heat load together with the ambient temperature via controlling the speed of condenser fan. Elsayed and Harir [3] investigated the effect of using a variable speed condenser fan on the performance and consuming power in small size air conditioner. They used a PID algorithm to control the condenser fan speed together with the ambient temperature. It was found that the compressor power consumption is reduced by $10 \%$ when the condenser fan's air flow increased by $50 \%$. Mohammed, et al. [4] investigated how the performance of a split air conditioning system could be improved via using a water mist PID controller. The water flow rate was controlled by varying the speed of the water pump using PID algorithm. The results show that the improved system provides better performance and energy saving than the conventional system. The (COP) are improved by $44.56 \%$, and over a wide range of ambient air temperatures up to $57^{\circ} \mathrm{C}$. Singh, et al. [5] designed and implemented a PID control system to improve the performance of an $\mathrm{A} / \mathrm{C}$ system through controlling the speed of condenser fan. This system had four input signals. These inputs receive signals denoted as an energy consumption value of a compressor, energy consumption value of a variable speed condenser fan, outdoor temperature, and condensation temperature, respectively. The output provides a control signal to the variable speed condenser fan. $\mathrm{Ng}$, et al. [6] investigated the possibility of executing a predictive controller for an Automotive Air Conditioning (AAC) provided with a Variable Speed Compressor (VSC) based on Adaptive Neural Network (ANN). A comparative evaluation is implemented between the adaptive controller and other two control schemes, known a Model Predictive Controller MPC based on offline trained ANN model and a conventional PID controller. The experimental results identify the supremacy of the proposed control scheme with reference tracking in addition to disturbance rejection caused by its adaptation capability in tacking over the real time AAC system behavior over the wide range of process conditions. Islam, et al. [7] analyzed an evaporately-cooled air-conditioning unit performance, experimentally and numerically. Experimental layout is performed by rebuilding commercially available air-conditioning unit and installing comprehensive instruments containing controllers and sensors. Experimental results showed that the increase of cooling effect and reduction of compressor lift improve the COP of the evaporately-cooled air-conditioning unit by about $28 \%$.

The literature survey revealed a number of studies in the field of performance improvement of a split $\mathrm{A} / \mathrm{C}$ system among them, using variable speed condenser fan algorithm [2] which used a CTC system equipped with air-cooled chillers. In contrast, the current study deals with PID algorithm prepared with the split-A/C system. Unlike the work of Elsayed and Harir [3] which uses a PID algorithm to control the speed of a AC fan, simultaneously with the ambient air temperature between $30^{\circ} \mathrm{C}$ and $42^{\circ} \mathrm{C}$, the current study uses a PID algorithm to control the speed of a proposed DC condenser fan that is compatible to the high speed range up to $2000 \mathrm{rpm}$. The speed is simultaneously controlled with the condenser saturation temperature $\mathrm{Tc}$, and the ambient air temperatures take rise between $35^{\circ} \mathrm{C}$ and $57^{\circ} \mathrm{C}$ to simulate a weather condition in IRAQ country. The work of Mohammed, et al [4] used a PID algorithm integrated with the water mist technology, while the present work uses a PID algorithm to adjust the speed of a condenser fan. The aim of this work is to enhance the performance of split $\mathrm{A} / \mathrm{C}$ system including parameters such as; compressor power consumption (Wcomp), cooling capacity (Qevap), condenser capacity (Qcond), $\mathrm{COP}_{\mathrm{U}}$, and $\mathrm{COP}$ at elevated ambient temperature. The variable speed of DC motor condenser fan adjusted over two intervals of ambient temperature $(35-40)^{\circ} \mathrm{C}$ and $(40-57)^{0}$ C. A Smart Control System (SCS) was designed and implemented to control the speed of the DC motor condenser fan via PID controller and PWM technique.

\section{Experimental Setup \\ 2.1 Split Air Conditioning System and Environmental Simulation Room (ESR)}

The split A/C system consists of the fundamental units of vapor compression system; condenser, evaporator, expansion valve, and compressor. A split A/C system is experimentally tested to determine an actual standard $\mathrm{A} / \mathrm{C}$ system performance. A schematic illustration of the experimental setup is shown in Fig. 1. The split $\mathrm{A} / \mathrm{C}$ system was tested under standard environment condition using ESR system shown in Fig. 2. The proposed system has $2.499 \mathrm{~kW}$ nominal capacity in addition to use refrigerant R22. The condensation unit has an AC propeller fan that replaced with a DC propeller fan that have some benefits if compared with $\mathrm{AC}$ fan such 
as: high efficiency, more energy saving, low noise, operate at low speed $1 / 3$ base speed, control flexibility, PWM technique easy to use, Operation temperature of DC fans less is than that of AC fans (less power consumed) [8]. The gas flow meter type KF500 shown in Fig. 2 is connected to the section line to measure a refrigerant flow rate. The ESR system is built to simulate the environment condition in Iraq. The ESR system consists of two separated zones: indoor unit zone and outdoor unit zone. The ESR system's construction and properties are:

1. Full isolated system using sandwich panel.

2. Manual temperature control system to adjust the temperature of indoor and outdoor zone at a desired value.

3. Two separated ducts system integrated with several stages of heater to supply air with a desired temperature for the two separate zones.

4. Full isolated watch glass to monitor the A/C system.

5. Control panel to monitor: temperature, DC voltage, DC current, AC voltage, AC current, and gas flow rate.

The ESR system is more compatible with the proposed control system SCS. ESR system gives more accuracy for the experiment results. It gives wide range of air temperature supplied to the indoor and outdoor units and also gives a good mixing, and distribution for temperature and air flow supplied to the indoor and outdoor units.

\subsection{Smart Control System (SCS) 2.2.1 Hardware Implementation}

The SCS system is controlled using Microchip (PIC16F877A) microcontroller as shown in Fig. 3. The SCS circuit design, construction, and development are programmed and simulate using Proteus Professional Software and PICBASIC Pro PBP compiler. The microcontroller PIC16F877A based automatic variable speed condenser fan system is applied to provide the functionality to implement automation characteristic. The condenser fan speed automatically change according to the condenser saturation temperature Tc. The SCS used a PID algorithm integrated on a PIC16F877A microcontroller to control the condenser fan according to the Tc variation. The control system measures the Tc coming from the Integrated Circuit (IC) LM35 and determines the error signal. The system indicates the Tc from the PIC16F877A and it displayed it on the Liquid Crystal Display (LCD). The condensation temperature is kept constant via PID controller over the ambient temperature $(35-40)^{0} \mathrm{C}$. Over this range the control system will change to constant mode with maximum speed. The ambient temperature data is acquired from other LM35DZ temperature sensor and comparing it with the condensation temperature data of the first LM35DZ to detect a malfunction caused by any leakage or condenser fan stop. The speed of condenser fan is controlled using PWM technique and Full H-Bridge Motor Driver BTS9760B, to control the input DC voltage [9], where:

$V_{\text {out }}=\frac{t_{\text {on }}}{T} V_{\text {in }}$

\subsubsection{Software Implementation}

The software is implemented to perform the following three functions:

1. PID controller with PWM technique for controlling the speed of condenser fan.

2. Refrigerant leak detection program.

3. Program detection for condenser fan stop and/or obstacles which opposes condenser air flow (condenser fins needed to be clean).

The flowcharts of these three programming modes are shown in Fig. 4.

\section{- PICBASIC PRO ${ }^{\mathrm{TM}}$ Compiler (PBP)}

This compiler is used to build a program and generate HEX file to setup a microcontroller PIC16F877A with PID algorithm and to generate PWM signals. The PICBASIC PRO ${ }^{\mathrm{TM}}$ Compiler (PBP) makes it even quicker and easier to any one for programming the Microchip Technology's powerful PIC@ microcontrollers [10].

\section{- Proteus Software}

Proteus 7.0 is a Virtual System Modeling (VSM) that combines circuit simulation, animated components and microprocessor models to cosimulate the complete microcontroller based designs. It is a good tool for engineers to test their microcontr4oller designs before constructing a physical prototype in the real world [11]. Fig. 5 shows the control circuit implementation and simulation with Proteus professional software.

\section{- CoolPack Software}

The CoolPack package is a general and comprehensive simulation program that would give the user all the flexibility in terms of handling many different system designs and 
investigation purposes. The CoolPack was developed in the Department of Energy Engineering in the Technical University of Denmark (DTU) (2001) [12].

\subsubsection{The Parameters Exactions for the Approximate Model of Condenser Unit}

The step response method is the better approximation model according to the actual response of the condenser plant. This response is a first order system with transportation delay. The response is represented by three parameters, $\mathrm{L}$ time delay, $\mathrm{K}$ forward gain and $\mathrm{T}$ time constant. These are found by drawing a tangent to the step response at its point of inflection and noting its intersections with the time axis and the steady state value as shown in Fig. 6. Fig. 7 shows the actual response of the condenser unit [13].

$G(s)=\frac{K e^{-s L}}{T s+1}$

where $\mathrm{L}=2.307$ sec, the $\mathrm{T}=5.3846 \mathrm{sec}$ and $\mathrm{K}=0.2267$. So, the transfer function is:

$G(s)=\frac{0.2267 e^{-s 2.307}}{5.3846 s+1}$

\subsubsection{PID Controller Design}

The open loop Ziegler-Nichols method (indirect method) is used to determine the PID controller coefficients $\mathrm{Kp}, \mathrm{Ki}$, and $\mathrm{Kd}$. This method is most known and most widely used for PID controller tuning in thermal application. The controller determines the error signal $e(t)$ that represents the difference between the desired and the measured value. This signal will generate a control signal. The drive control signal is $u(t)$. The PID controller can be mathematically represented by:

$u(t)=\mathrm{kp} e(\mathrm{t})+\mathrm{Ki} \int \mathrm{e}(\mathrm{t})+\mathrm{Kd} \frac{d e(t)}{d t}$

This equation can also be represented in the $S$ domain by applying the Laplace transform, as follows:
$U(s)=\mathrm{E}(\mathrm{s})\left(\mathrm{Kp}+\frac{\mathrm{Ki}}{\mathrm{s}}+\mathrm{Kd} \mathrm{S}\right)$

With zero initial conditions, the gains of the three terms of the controller (the proportional $\mathrm{Kp}$, derivative $\mathrm{Kd}$ and integral $\mathrm{Ki}$ ) are set by using ZNM. The gains $\mathrm{Kp}, \mathrm{Kd}$ and $\mathrm{Ki}$ are evaluated by using controller parameters $(\mathrm{K}, \mathrm{L}$, and $\mathrm{T})$ of $\mathrm{G}(\mathrm{s})$, which are experimentally evaluated [13]:

$\mathrm{Kp}=1.2 \mathrm{~T} / \mathrm{K} * \mathrm{~L}$

$\mathrm{Ti}=2 \mathrm{~L}$

$\mathrm{Td}=0.5 \mathrm{~L}$

The obtained results are: $\mathrm{Kp}=12.3547 ; \mathrm{Ti}=$ $4.614 \mathrm{sec} ; \mathrm{Td}=1.1535 \mathrm{sec}$, so:

$\mathrm{Ki}=\frac{\mathrm{Kp}}{\mathrm{Ti}}=2.6776$

$\mathrm{Kd}=\mathrm{KpTd}=14.2511$

After experimentally fine tuning, the PID coefficients were found as follows: $\mathrm{Kp}=10.23$, $\mathrm{Ki}=1.92$, and $\mathrm{Kd}=12.35$.

\section{Formula Used}

The parameters used for investigating the performance of each system can be computed via the following equations [14]:

1. Heat transfer of condenser is computed by equation:

$Q_{\text {cond }}=\dot{m}_{r}\left(h_{2}-h_{3}\right)$

2. Heat transfer at evaporator can be calculated as:

$Q_{\text {evap }}=\dot{m}_{r}\left(h_{1}-h_{4}\right)$

3. Power consumed by a compressor:

$\mathrm{W}_{\mathrm{c}}=\mathrm{V} \times \mathrm{I} \times \operatorname{Cos} \Theta$

4. Coefficient of Performance (COP):

$$
\text { C. O.P }=\frac{Q_{\text {evap }}}{W_{c}}
$$

5. Heat rejection ratio $=\frac{\text { condeser capacity }}{\text { coolingcapacity }}$

6. $\mathrm{COP}_{\mathrm{U}}=\frac{\text { cooling acpacity }(\mathrm{kW})}{\text { total input power }(\mathrm{kW})}$ 

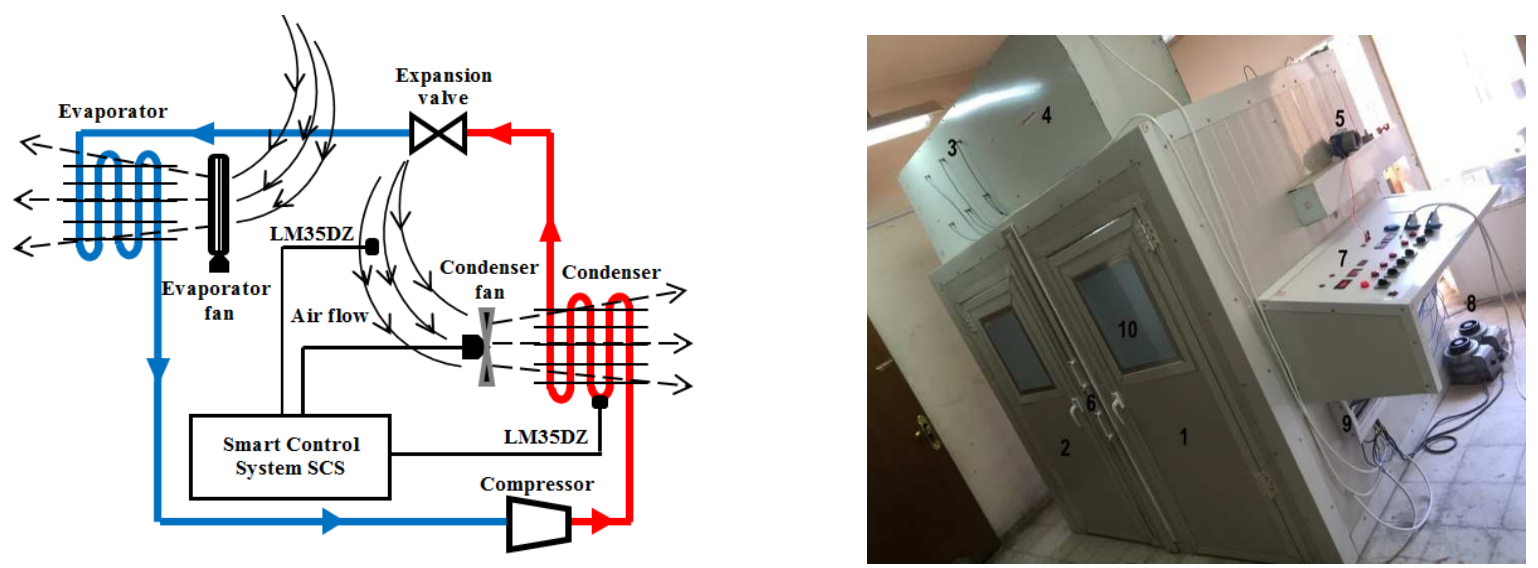

(a)

Fig. 1. A schematic view of the experimental apparatus.

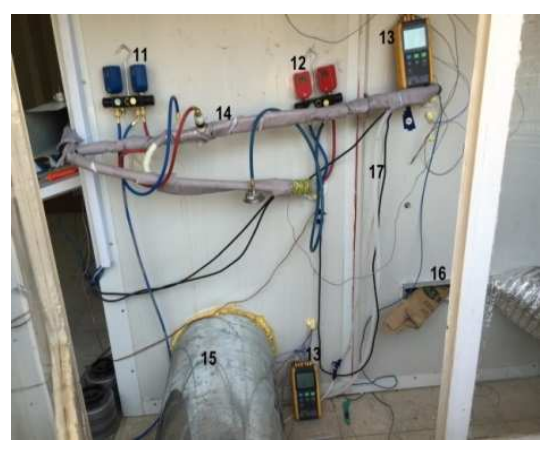

(b)

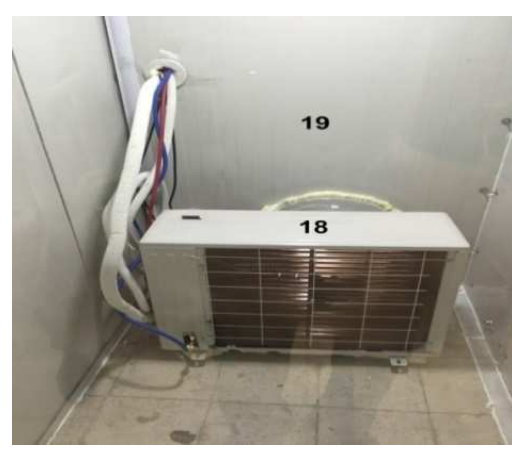

(c)

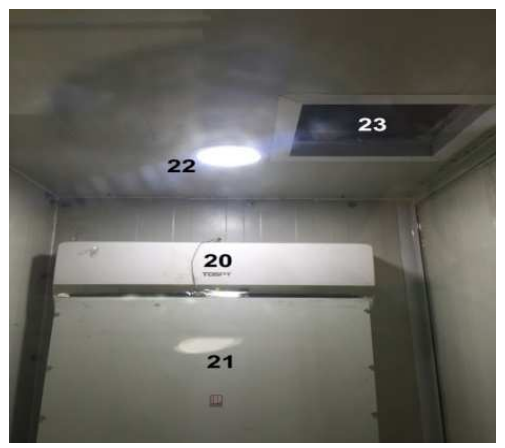

(d)

\begin{tabular}{llll}
\hline No. & Components & No. & Components \\
\hline 1 & Indoor unit zone & 13 & Temperature recorder \\
2 & Outdoor unit zone & 14 & Pipe line \\
3 & Heaters & 15 & Indoor unit discharge duct \\
4 & Duct system & 16 & outdoor unit discharge duct \\
5 & Gas flow meter, KF500 & 17 & Evaporator drain \\
6 & Slide wall & 18 & Condensing unit \\
7 & Control panel & 19 & Inside outdoor unit zone \\
8 & VARIAC & 20 & Evaporating unit \\
9 & Main Circuit breaker & 21 & Discharge duct \\
10 & Watch glass & 22 & Spot LED \\
11 & Low pressure side gages & 23 & Supply duct to indoor unit zone \\
12 & High pressure side gages & & \\
\hline
\end{tabular}

Fig. 2. ESR System: (a) Overall ESR System, (b) Pipes, Air Duct, and Measurements, (c) A/C Outdoor Unit , (d) A/C Indoor Unit.

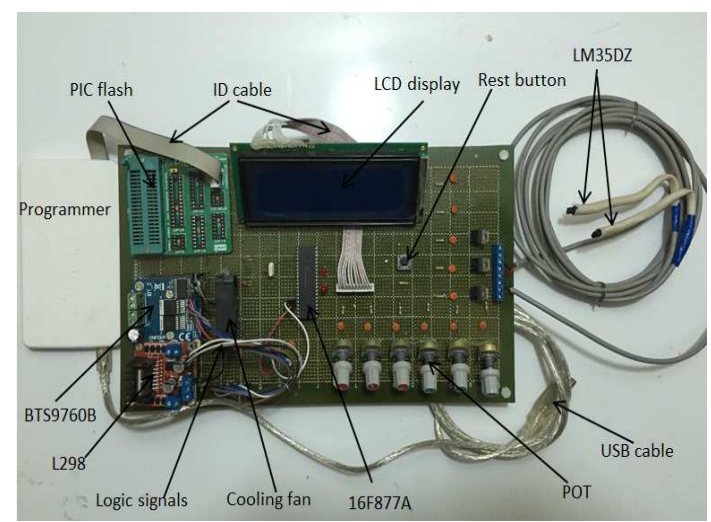

Fig. 3. The Smart Control System SCS. 


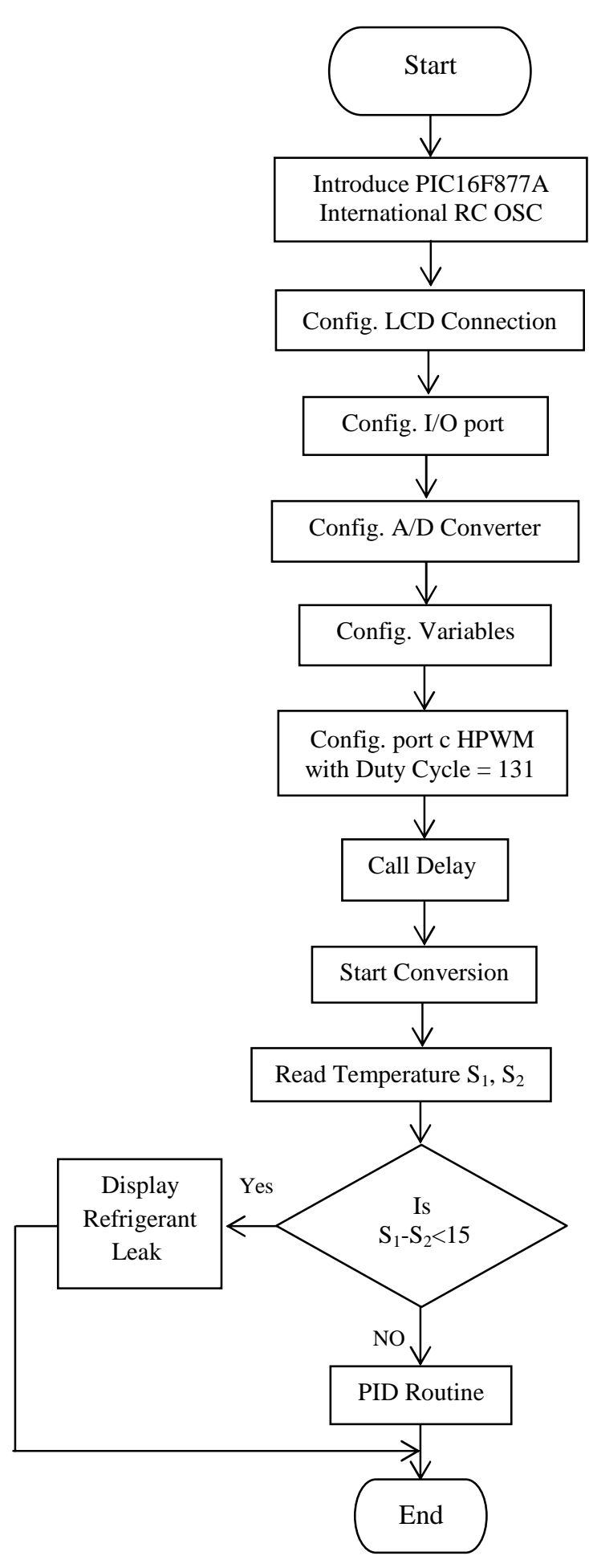

(a)

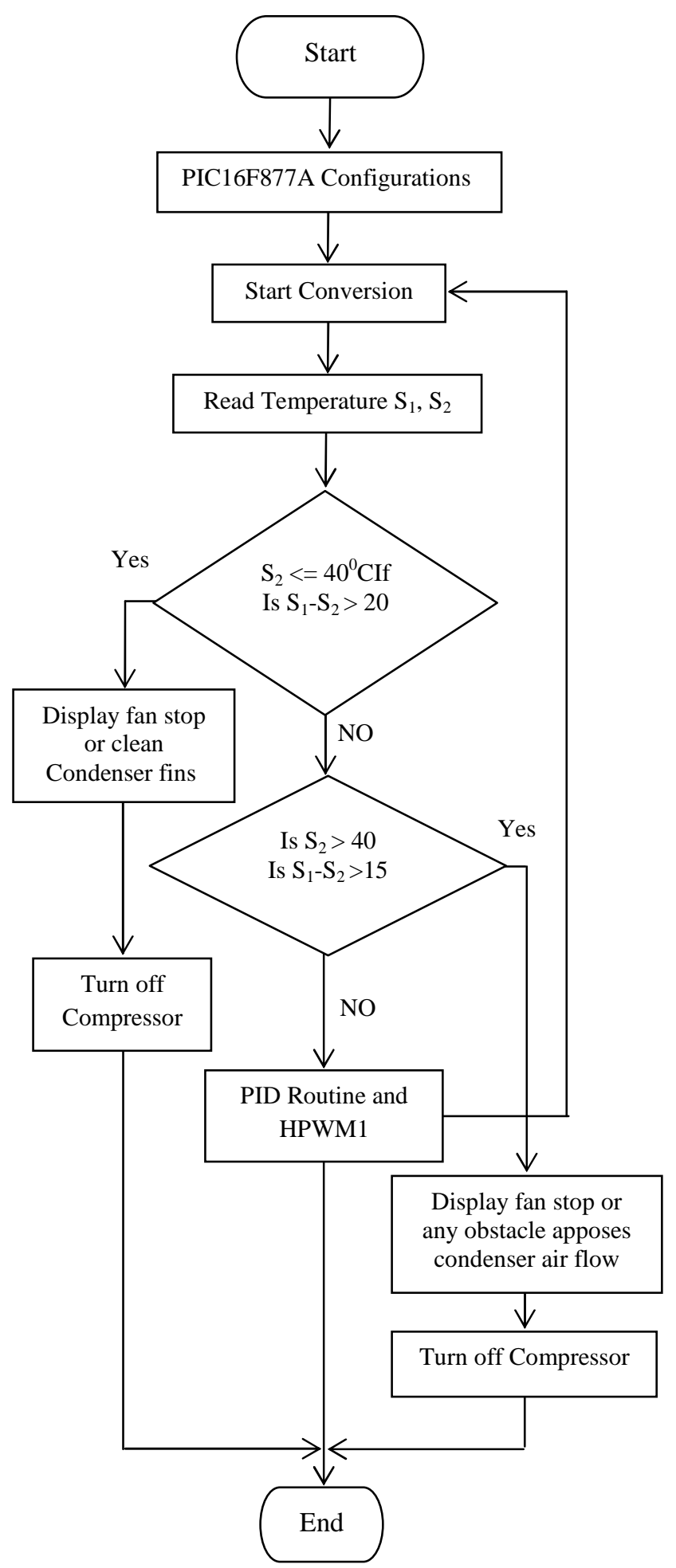

(b) 


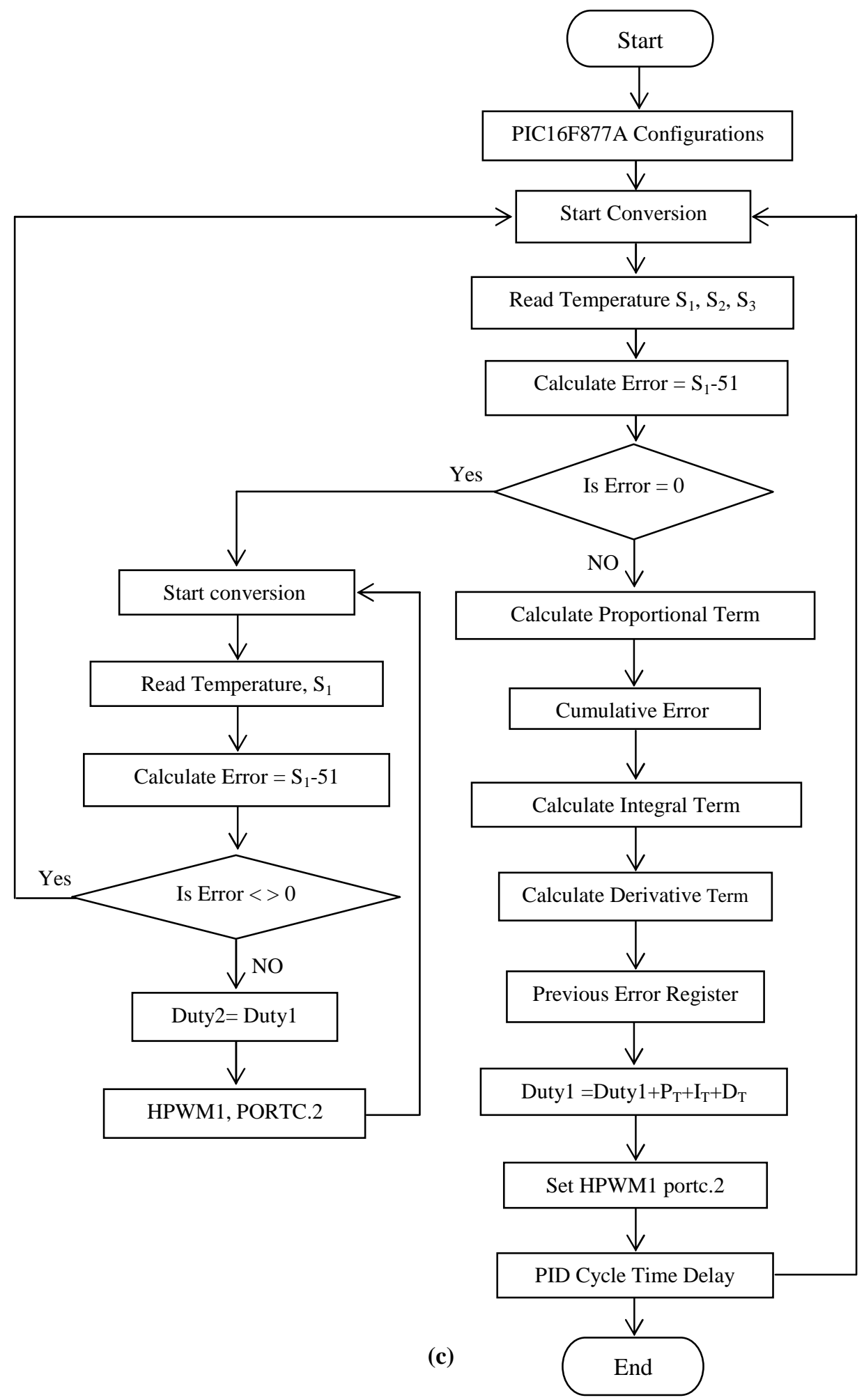

Fig. 4: Flowcharts for: a) PIC configurations and leak detection scheme, b) PID routine scheme for fan stop and obstacles detection, c) PID routine scheme 


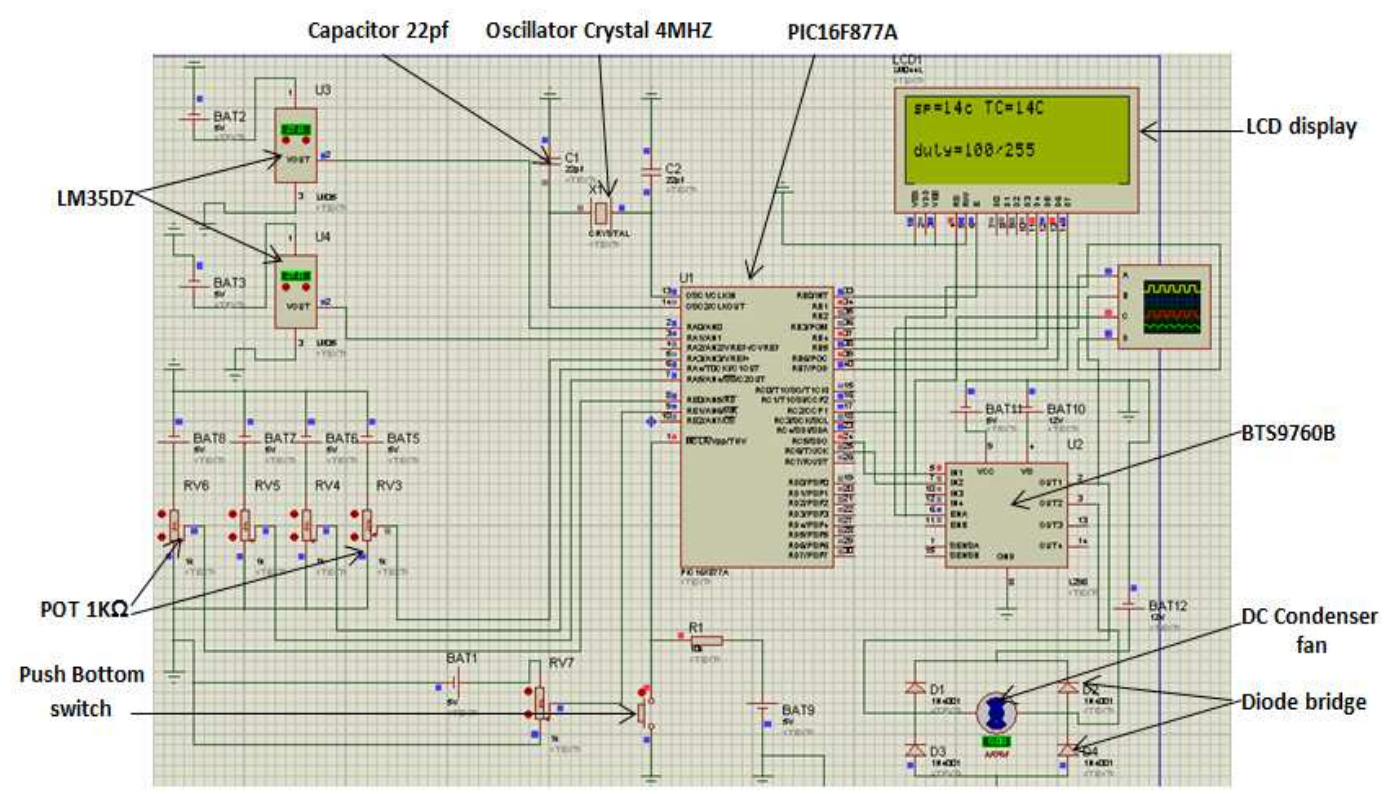

Fig. 5. control circuit implementation and simulation with Proteus professional software.

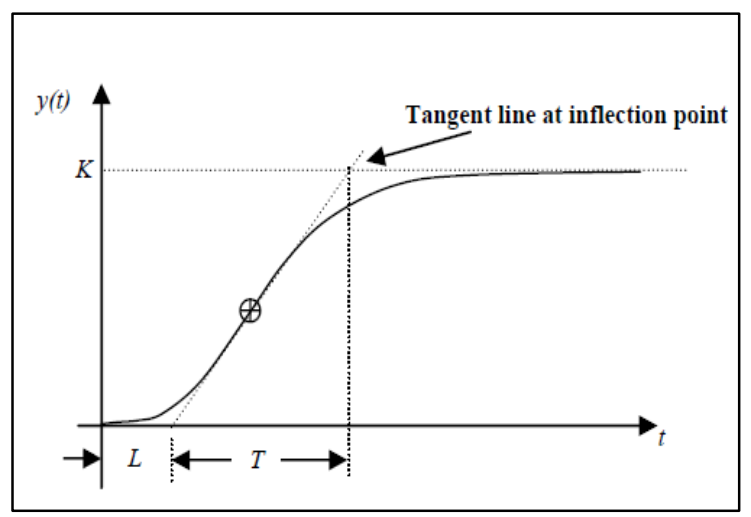

Fig. 6. Scheme of identification method.

\section{Results and Discussion}

The ambient air temperature effected the performance and the energy saving of an $\mathrm{A} / \mathrm{C}$ system. As the air flow increase of condenser fan the heat recovery for the condensing unit increase, consequently the condensing temperature will decrease. In the case of studying the effect of using a PID controller on the system performance, it is found that, when the PID controller is processing over the range $(35-40)^{0} \mathrm{C}$ of ambient temperature, the performance coefficients of split $\mathrm{A} / \mathrm{C}$ system have a good arrangement with very small deviation from the programmed performance at $35^{\circ} \mathrm{C}$ ambient temperature, while at the constant mode operation with the maximum fan speed and over the range $(41-57)^{\circ} \mathrm{C}$ ambient temperature, the performance coefficients have been improved, but not as the previous range. Fig.

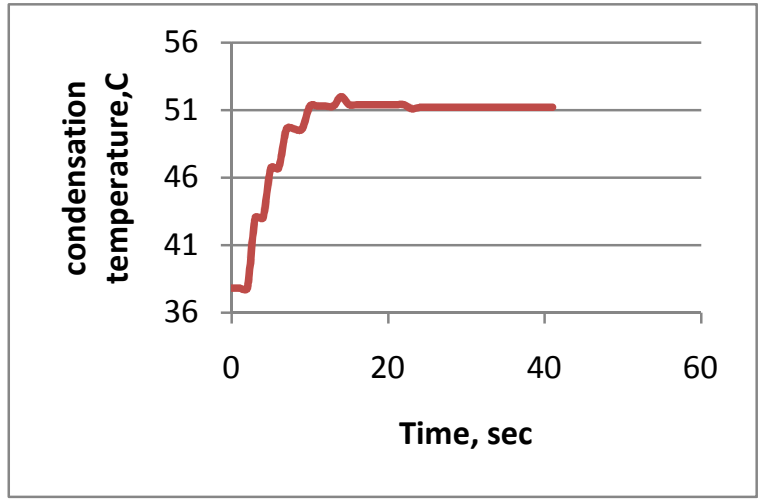

Fig. 7. Actual response.

8 shows the effect of variation condenser inlet air temperature on the refrigeration cooling capacity. It is clear that the cooling capacity was increased as a PID controller is used due to the increase of air flow rate as shown in Fig. 9. The increase of air flow will decrease the condensation temperature, due to increase the heat rejected by the condenser unit as shown in Fig. 10 . At $40^{\circ} \mathrm{C}$ and $57^{\circ} \mathrm{C}$ ambient temperature, the cooling capacity of the conventional system decreased by $7.80 \%$ and $30.77 \%$, respectively, while for the proposed system are decreased by $0.88 \%$ and $19.36 \%$. Fig.11 shows the effect of condenser inlet air temperature variation on the condenser capacity. It is clear that the condenser capacity is increased after using a PID controller due to increase the air flow rate. The increase of air flow decreases the condensation temperature, due to increase the heat rejected. For proposed system, 
the decrease of condensation temperature is caused by increasing of compressor volumetric efficiency, due to decrease of pressure ratio. The condenser capacity of the conventional system at $40^{\circ} \mathrm{C}$ and $57^{\circ} \mathrm{C}$ are decreased by $5.77 \%$ and $23.86 \%$ respectively, and for the enhanced system decreased by $0.86 \%$ and $14.85 \%$ respectively. Fig. 12 shows the effect of variation condenser inlet air temperature on the COP. It is clear that, the COP is increased after adding a PID controller due to increase the cooling capacity and the decrease of compressor power consumption as shown in Fig.13. The decrease of the condensation temperature increases the cooling capacity as well as the refrigerant flow rate as shown in Fig.14. The COP of the conventional system decreased at $40{ }^{\circ} \mathrm{C}$ and $57{ }^{\circ} \mathrm{C}$ by $18.83 \%$ and $56.97 \%$ respectively, and for the enhanced system decreased by $1.8 \%$ and $36.41 \%$. Fig. 15 shows the effect of condenser inlet air temperature variation on the $\mathrm{COP}_{\mathrm{U}}$. It is clear that, the $\mathrm{COP}_{\mathrm{U}}$ was improved with adding a PID controller due to decrease of compressor power consumption and increase of refrigeration cooling capacity. As the condensation temperature decrease the heat rejection ratio decrease as shown in Fig.16. This lead to decrease the compressor power consuming gained. The gained of $\mathrm{COP}_{\mathrm{U}}$ for the conventional system at $40^{\circ} \mathrm{C}$ and $57^{\circ} \mathrm{C}$ are decreasing by

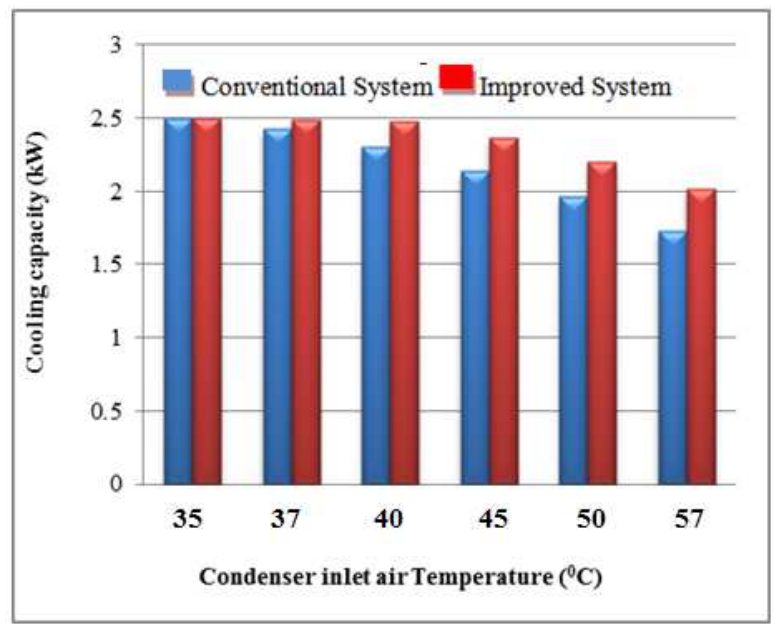

Fig. 8. Effect of condenser inlet air temperature variation on cooling capacity.
$17.13 \%$ and $56.04 \%$ respectively, but for the enhanced system are decreased by $14.03 \%$ and $43.6 \%$. Fig.17 shows the difference between refrigerant pressures in/out put of the condenser and the pressure drop caused by the condenser unit. Fig.18 show the difference between refrigerant pressures in/out put of the evaporator and the pressure drop caused by the evaporator unit. It can be shown that the pressure drop increases with the increase of ambient temperature. Fig.19 shows the variation of evaporating tepmerature via variation of condenser inlet air temperature at $27^{\circ} \mathrm{C}$ inlet air temperature to evaporator. Fig.20 and Fig.21 show the output of CoolPack software for the conventional and improved system. These figures present the performance of the two systems on $\mathrm{p}-\mathrm{h}$ diagram with the variation of ambient temperature over the range $(35-57)^{0} \mathrm{C}$. It is clear that the performance of the system after addition of PID controller is improved through decrease of head pressure due to increase the heat rejected by the condenser unit.

Detection system of three cases has been tested in practice and gave the desired results. Leak detection system, Fan stop detection, and Obstacles in the fan pathway detection through giving alert on LCD display.

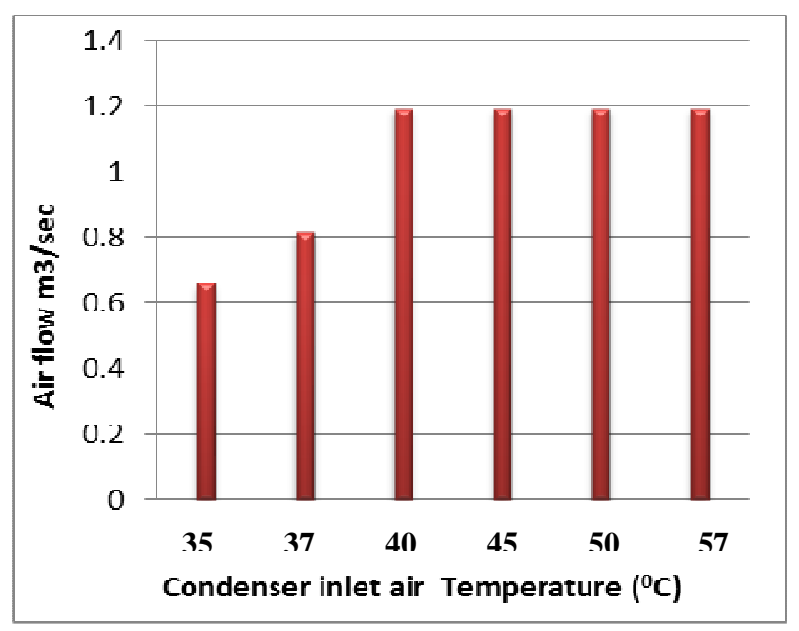

Fig. 9. Air flow variation via condenser inlet air temperature. 


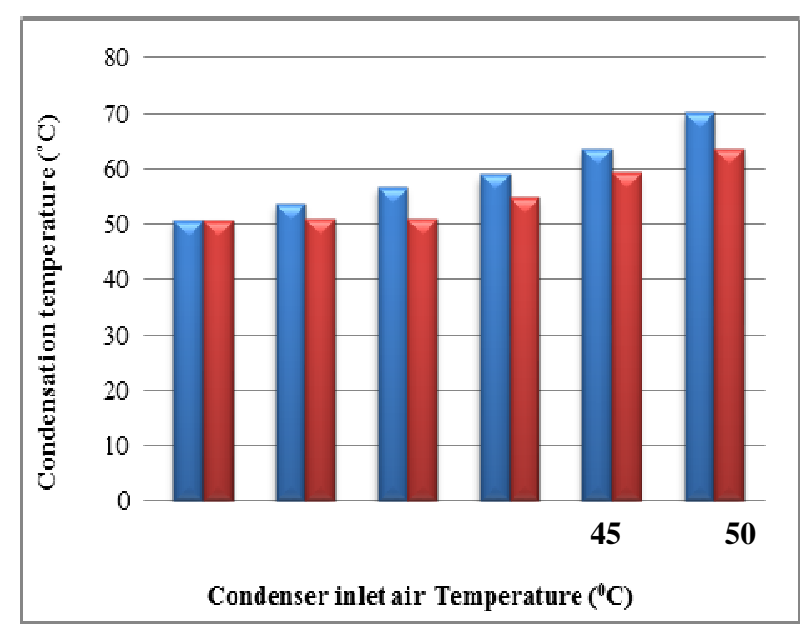

Fig. 10. Condensation temperature variation for convensional and improved system.

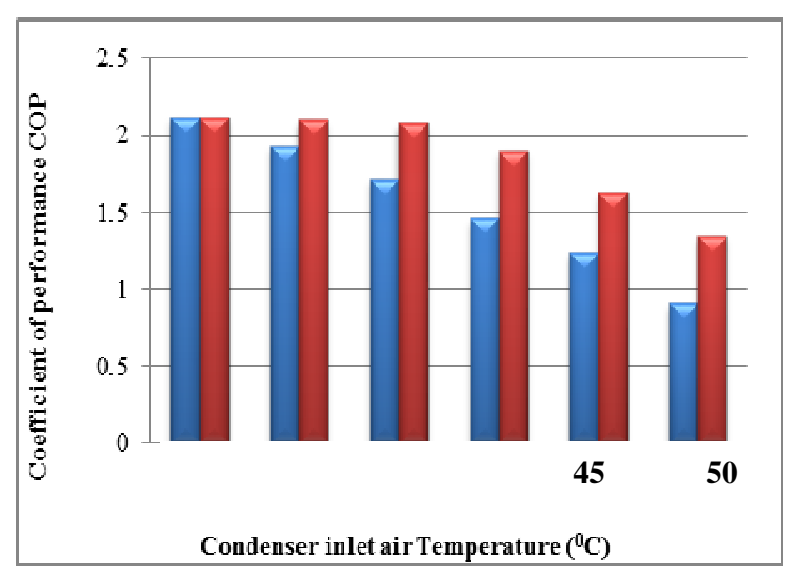

Fig. 12. Effect of condenser inlet air temperature variation on COP.

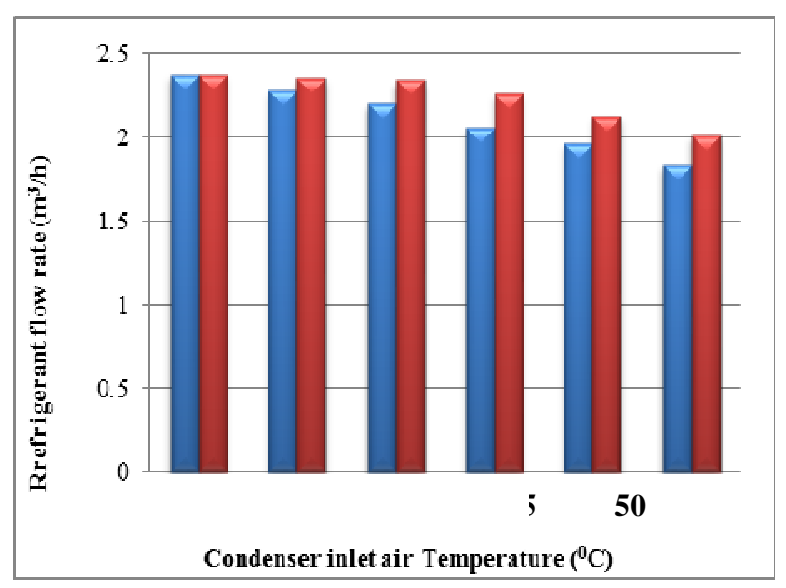

Fig. 14. Effect of condenser inlet air temperature variation on refrigerant flow for the two systems.

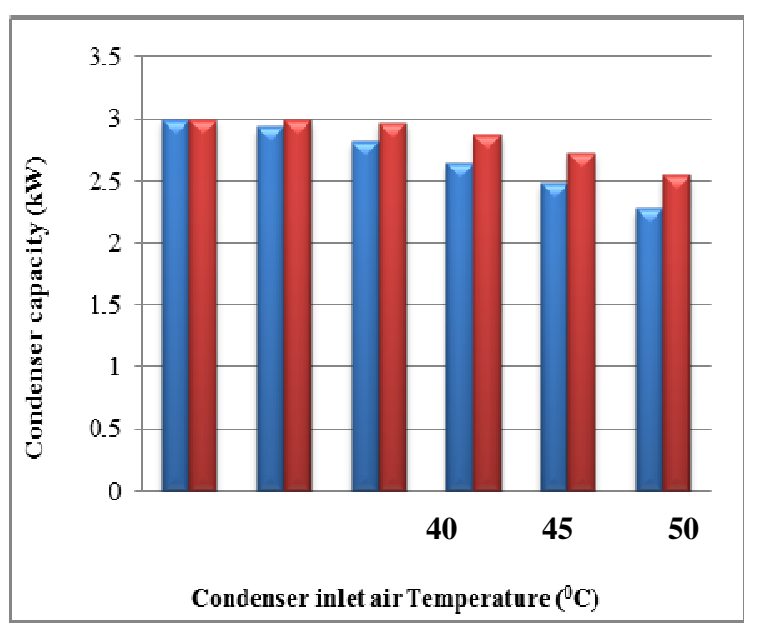

Fig. 11. Effect of condenser inlet air temperature temperature variation on condenser capacity.

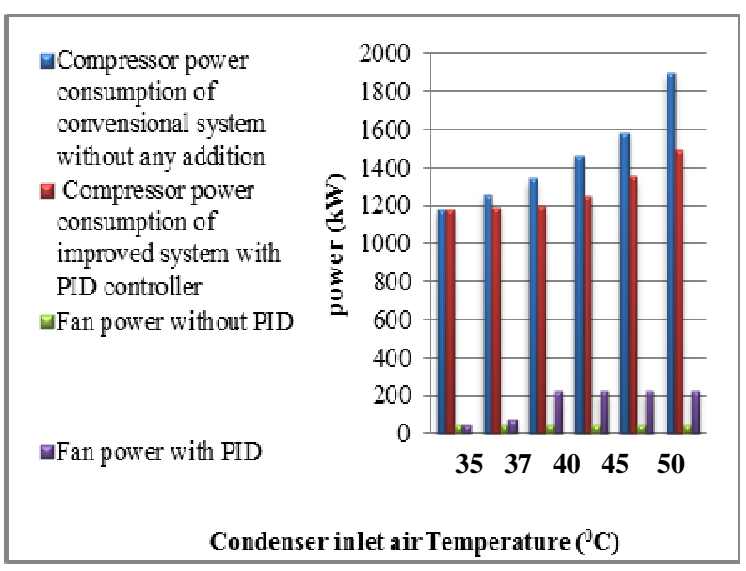

Fig. 13. Effect of condenser inlet air temperature variation on compressor power consumtion.

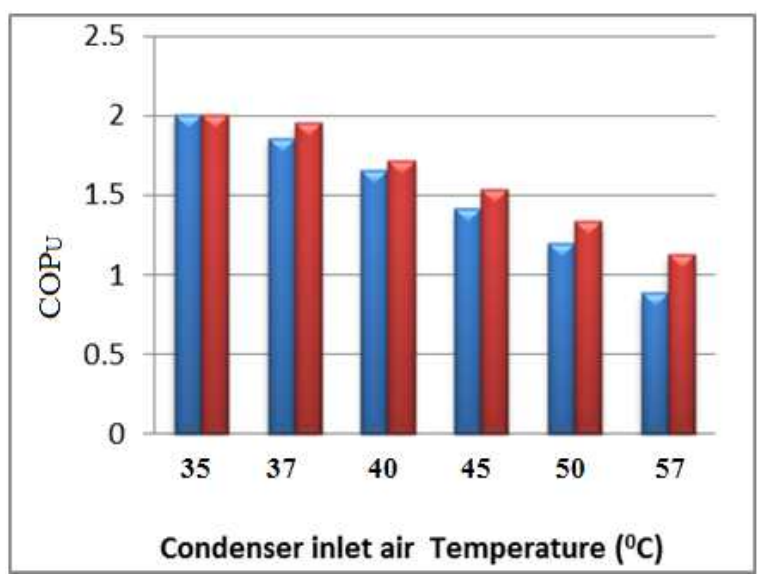

Fig 15. Effect of condenser inlet air temperature variation on unit coefficient of performance. 


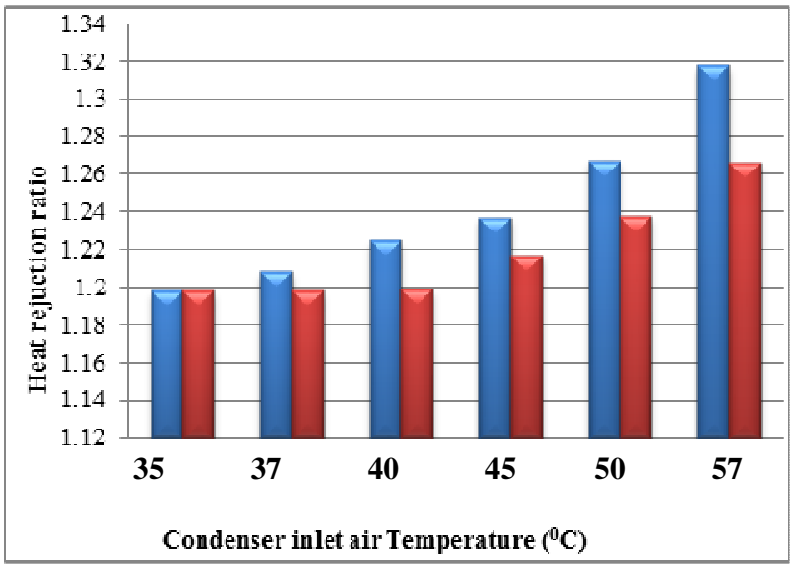

Fig. 16. Effect of condenser inlet air temperature variation on heat rejuction ratio.

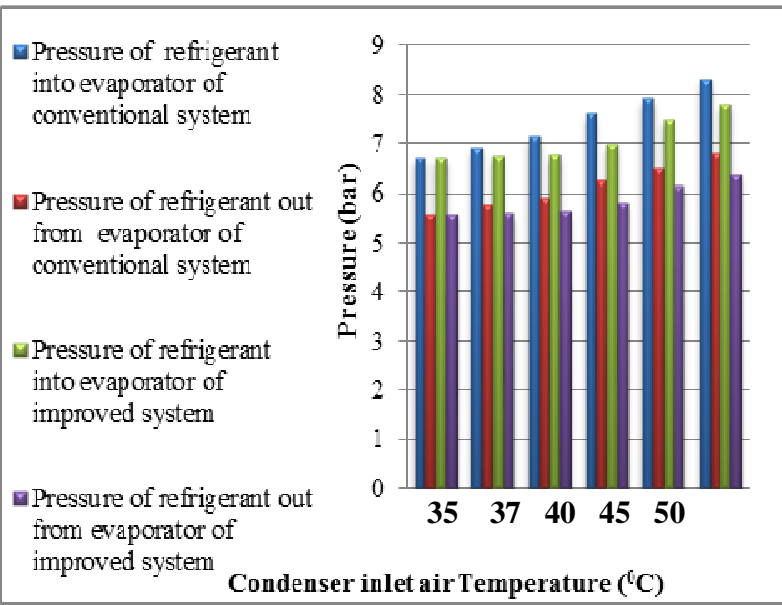

Fig. 18. Evaporator pressure in/out variation with the variationof condenser inlet air temperature.

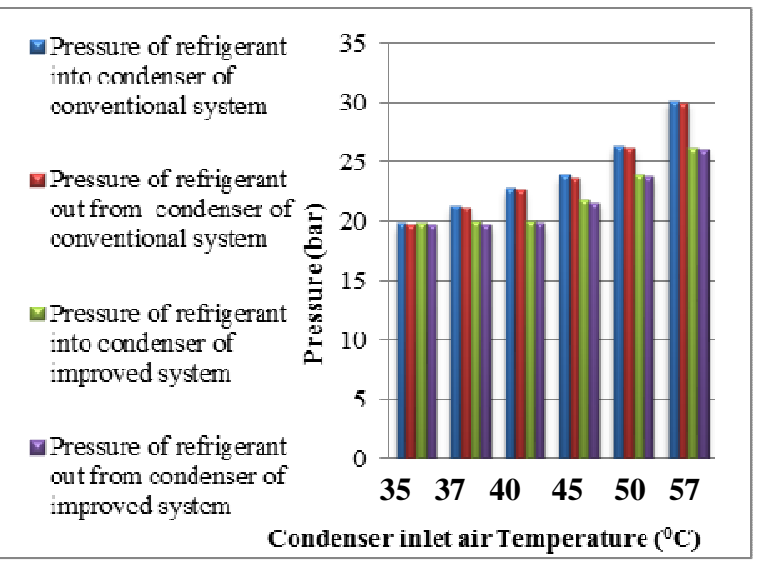

Fig. 17. Condenser pressure in/out variation with the variation of condenser inlet air temperature.

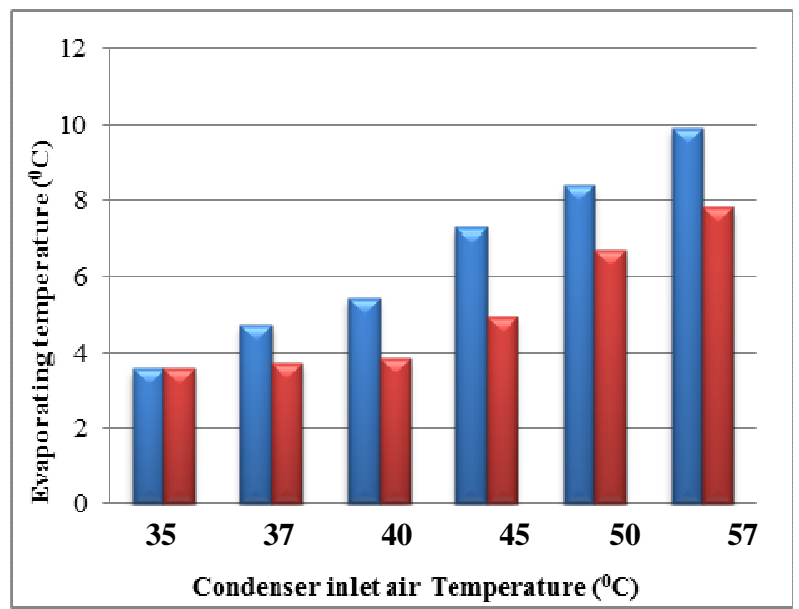

Fig. 19. Variation of evaporating temperature via vartiation of condenser Inlet air temperature at $27^{\circ} \mathrm{C}$ temperature to evaporator.

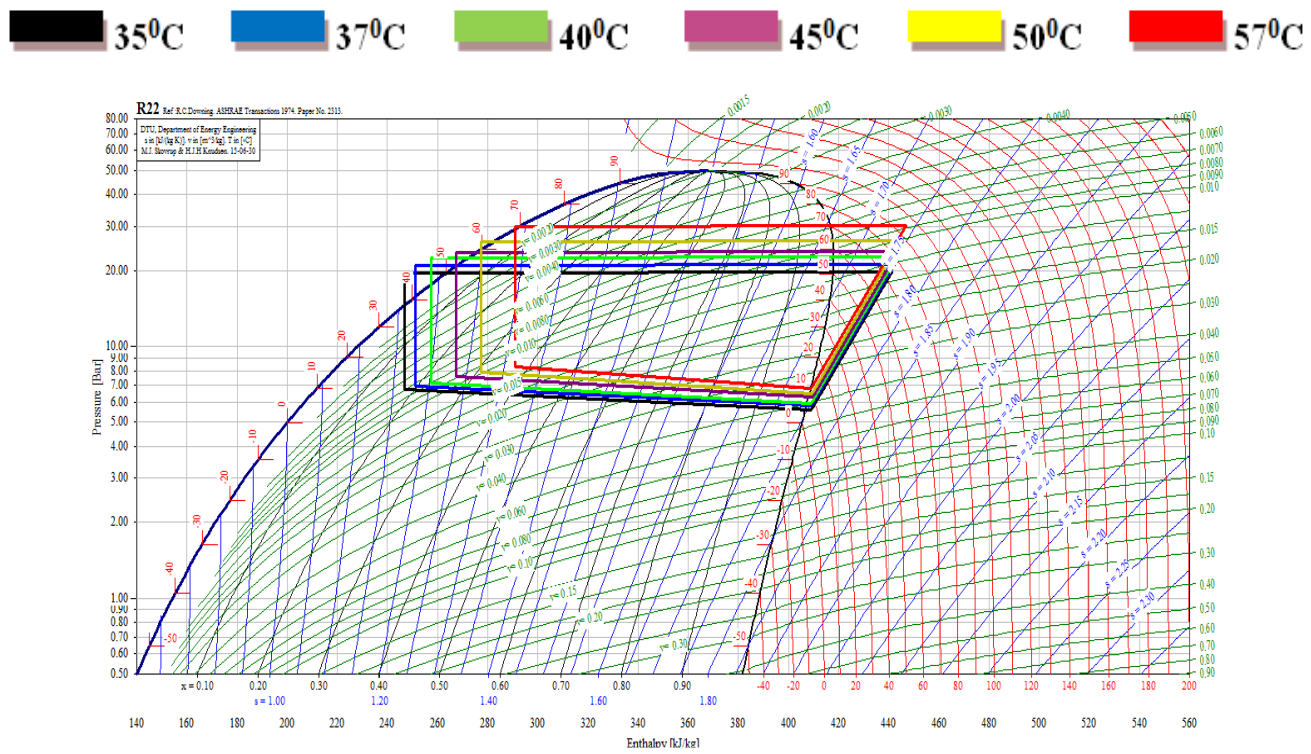

Fig. 20. p-h diagram for conventional system over $(35-57)^{0} \mathrm{C}$. 


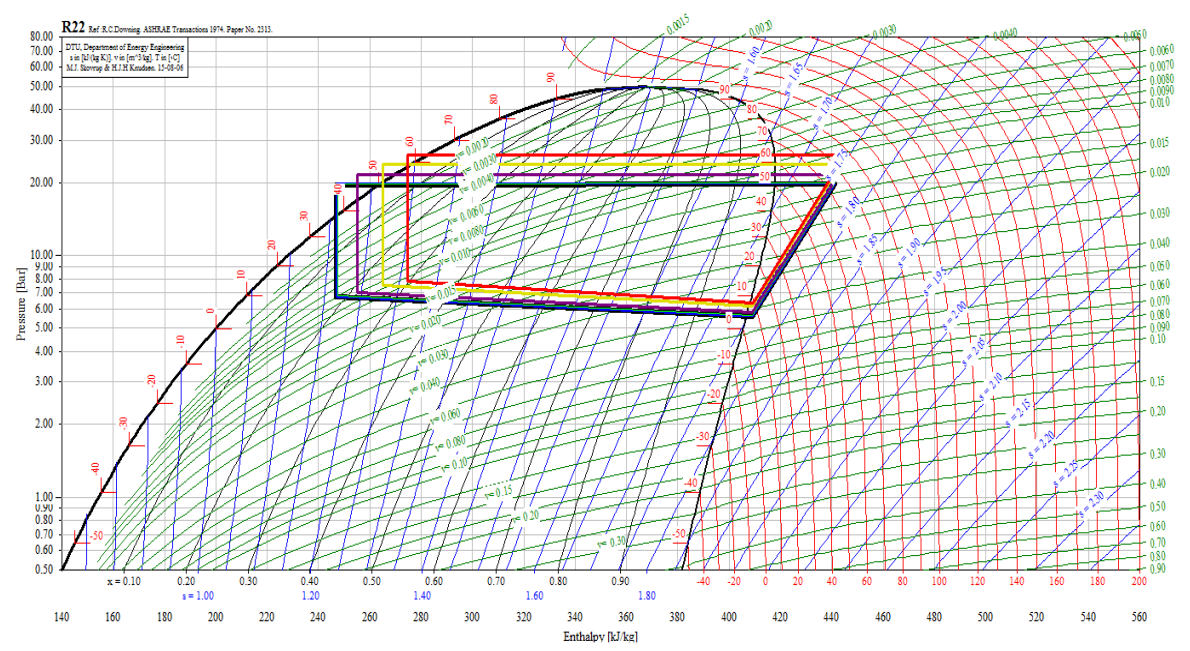

Fig. 21. p-h diagram for improved system over $(35-57)^{0} \mathrm{C}$.

\section{Conclusions}

This work investigates the performance enhancement of a split $\mathrm{A} / \mathrm{C}$ system, in the hot weathers. The PID controller has been successfully integrated with SCS with low cost and high efficiency. From the experimental results obtained, the following concluding remarks drawn:

1. The use of PID controller were achieved a good performance improvement for the $\mathrm{A} / \mathrm{C}$ system, specifically, over the range $(35-40)^{0} \mathrm{C}$ ambient temperature.

2. The compressor power consumption has been reduced by (5.96-34.09)\% over the range (3757) ${ }^{0} \mathrm{C}$ ambient temperature.

3. The decreasing rate of cooling capacity, condenser capacity, COP, and $\mathrm{COP}_{\mathrm{U}}$ for the proposed system is lower than the conventional system.

4. Fault detection can easily use with the proposed SCS, which add additional reliability, stability, safe operation, protection and long life of the $\mathrm{A} / \mathrm{C}$ system parts.

5. The proposed SCS is more compatible with the weather condition in IRAQ country, and the using of it in large scale A/C systems may give big amount of overall energy saving.

\section{Nomenclature}

$\begin{array}{ll}\text { Abbreviation } & \begin{array}{l}\text { Meaning of Abbreviation } \\ \text { air conditioning system }\end{array} \\ \text { AC } & \text { alternative current } \\ \text { COS } & \text { Power factor } \\ \text { COP } & \text { coefficient of performance } \\ \text { COP }_{U} & \text { Unit coefficient of performance }\end{array}$

\begin{tabular}{|c|c|}
\hline DC & direct current \\
\hline $\mathrm{h}_{1}$ & $\begin{array}{l}\text { Enthalpy of refrigerant out from } \\
\text { evaporator }(\mathrm{kJ} / \mathrm{kg})\end{array}$ \\
\hline $\mathrm{h}_{2}$ & $\begin{array}{l}\text { Enthalpy of superheated refrigerant } \\
(\mathrm{kJ} / \mathrm{kg})\end{array}$ \\
\hline $\mathrm{h}_{3}$ & $\begin{array}{l}\text { Enthalpy of sub-cooled refrigerant } \\
(\mathrm{kJ} / \mathrm{kg})\end{array}$ \\
\hline $\mathrm{h}_{4}$ & $\begin{array}{l}\text { Enthalpy of refrigerant entering to } \\
\text { evaporator }(\mathrm{kJ} / \mathrm{kg})\end{array}$ \\
\hline $\mathrm{I}$ & Compressor input current (Amp) \\
\hline $\mathrm{Kd}$ & Derivative Gain \\
\hline $\mathrm{Ki}$ & Integral Gain \\
\hline $\mathrm{Kp}$ & Proportional gain \\
\hline $\mathrm{mr}$ & Refrigerant mass flow rate $(\mathrm{kg} / \mathrm{sec})$ \\
\hline$Q_{\text {cond }}$ & Condenser capacity (Kw) \\
\hline Qevap & Cooling capacity $(\mathrm{Kw})$ \\
\hline RH & Relative humidity \\
\hline Tc & $\begin{array}{l}\text { condenser saturation temperature } \\
\text { (0C) }\end{array}$ \\
\hline $\mathrm{T}$ & Period of PWM signal (sec) \\
\hline ton & Time ON of switching (sec) \\
\hline V & Compressor supply voltage (volt) \\
\hline Vin & $12 \mathrm{~V}$ battery to supply voltage (volt). \\
\hline Vout & $\begin{array}{l}\text { Average voltage supply to DC fan } \\
\text { motor (volt) }\end{array}$ \\
\hline Wcomp & Compressor input power (Watt) \\
\hline
\end{tabular}

\section{Notation}

$\begin{array}{ll}133 & \text { Standard duty cycle at } 35 \mathrm{C}^{0} \\ 40 \mathrm{C}^{0} & \text { Ambient temperature } \\ 20 \mathrm{C}^{0} & \begin{array}{l}\text { Temperature difference between } \mathrm{T}_{\mathrm{c}}\left(\mathrm{S}_{1}\right) \\ \text { and ambient }\left(\mathrm{S}_{2}\right)\end{array} \\ 51 & \text { Tc set point temperature or desired } \\ & \text { temperature }\end{array}$




\section{References}

[1] Iraqi meteorological organization and seismology, 2015, www.meteoseism.gov.iq.

[2] F. W. Yu and K. T. Chan, "Advanced Control of Heat Rejection Airflow for Improving the Coefficient of Performance of Air Cooled Chillers", Applied Thermal Engineering, Vol. 26, Issue 1, January 2006, pp. 97-110.

[3] A. O. Elsayed and A. S. Harir, "Effect of Condenser Air Flow on the Performance of Split Air Conditioner", World Renewable Energy Congress, Conference Paper, 8-13 May 2011, pp. 2134-2141.

[4] F. M. Mohammed, J. A. Mohammed, and M. A. Jabbar," Energy Saving and Performance Improvement of a Split Air Conditioning System Using Water Mist PID Controller", Wulfenia Journal, Vol. 22, Issue 9, Sep. 2015, pp. 96-104.

[5] A. Singh, Thomas J. M., Frank C., and Ozgur Y.G, Variable Speed Condenser Fan Control System, United States Patent, US 7,845,183 B2, Dec. 7, 2010.

[6] B. C. Ng, I. Z. M. Darus, H. Jamaluddin, and H. M. Kamar, "Application of adaptive neural predictive control for an automotive air conditioning system", Applied Thermal Eng. Vol. 73, Issue 1, Dec. 2014, pp. 12421252.

[7] M.R. Islam, K.A. Jahangeer, and K. J. Chua, "Experimental and numerical study of an evaporatively-cooled condenser of airconditioning systems", Energy, Vol. 87, Issue 1, July 2105, pages 390-399.

[8] Engineers Edge, LLC, Improving Fan System Performance, Sourcebook for Industry, U.S. Department of Energy Efficiency and Renewable Energy, April 2003

[9] Austin Hughes, Electric Motors and Drives Fundamentals: Types and Applications, 3rd Edition, Elsevier Ltd, 2006.

[10] Dogan Ibrahim, PICBASIC PROJECT, Linacre House, Jordan Hill, Oxford OX2 8DP, UK, 2006.

[11] Xtronic Circuits, Proteus 7, http://xtronic.org/download/proteus-7-aresisis/.

[12] Jakobsen, A., Rasmussen, B., D., Skovrup, and M., J. Engedal, Simulation program handling many different system designs and investigation purposes, A CoolPack Package, Department of Energy Engineering, Technical University of Denmark (DTU), 2001.

[13] Karl Johan, Aström , and Richard M. Murray, Feedback Systems, An Introduction for Scientists and Engineers, Version v2.10c, Princeton University Press, pp302, March 4, 2010.

[14] G. F. Hundy, A. R. Trott and T. Welch, Refrigeration and Air-Conditioning, 4th Edition, Elsevier Ltd, 2008. 


\title{
استخدام نظام سيطرة ذكي لتحسين اداء منظومات التكييف ذات الوحدات المنفصلة
}

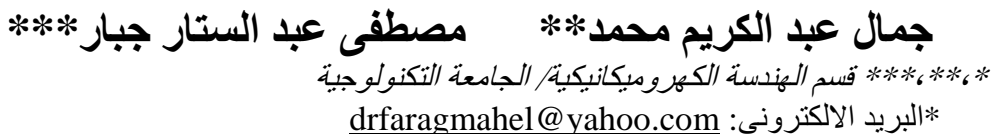 \\ البريد الاكتروني: الاكترني \\ jamalshwesh@gmail.com البريد الالكتروني: الالكتروني: \\ mustafa4eem@yahoo.com البريد الالكتروني: البروني:
}

فرج محل محمد*

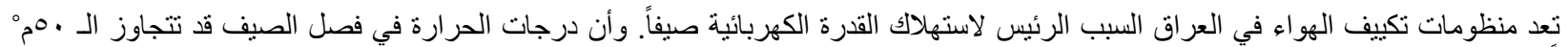

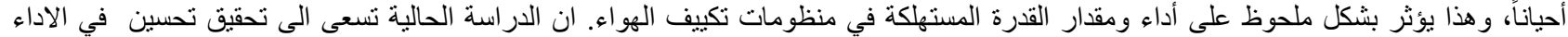

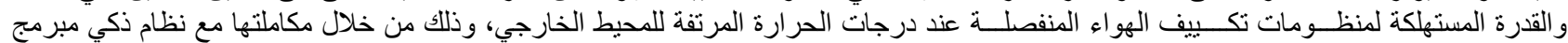

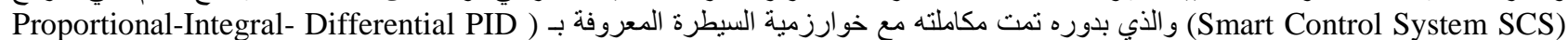

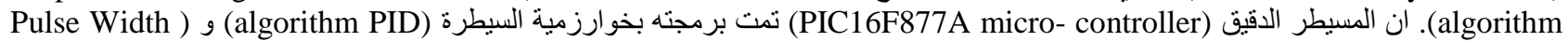

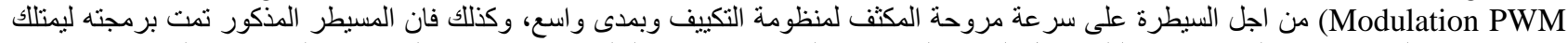

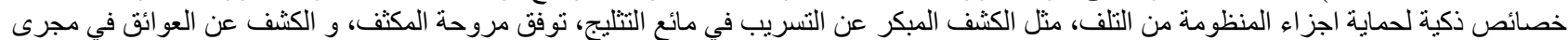

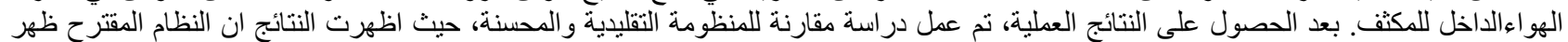

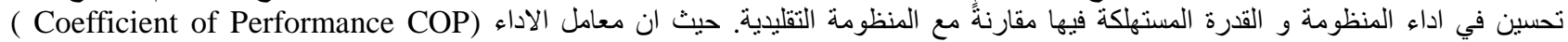
r. 